\title{
VIABILIDADE DO USO DE HERBICIDAS EM MISTURA COM VINHACA PARA O CONTROLE DE PLANTAS DANINHAS EM SOQUEIRAS DE CANA-DE-AÇÚCAR
}

\author{
A. Buss*, N.A. da Glória** \& O.A. Jacintho** \\ * Pesquisador - Depto. Pla nej amento e Opera - \\ ções EMPASC - Florianópolis \\ ** Professores - Depto. de Química-ESALQ Pira- \\ cicaba \\ Parte da dissertação de mestrado do primeiro \\ autor. \\ Recebido para publicação em 19.06.78.
}

\section{RESUMO}

No presente estudo comparou-se a aplicação de herbicidas em mistura com vinhaça, com aplicação pelo sistema convencional, em soqueira de cana-de-açúcar. Os herbicidas usados foram oryzalin, diuron, 2,4-D, ametryne e tebuthiuron. A aplicação em mistura com vinhaça foi feita com caminhão-tanque com capacidade para 7000 litros, provido com uma barra de distribuição de vazão controlada. A dose de aplicação foi de 25.0001 /ha. A distribuição dos herbicidas com equipamento convencional foi feita com pulverizador John Bean", provido com 16 bicos "Teeject" 110.04, trabalhando com pressão de $1,4 \mathrm{~kg} / \mathrm{cm}^{2}$. Usou-se delineamento experimental de blocos casualizados com parcelas subdivididas, com quatro repetições.

Pelos resultados obtidos constatou-se que, à excecão do diuron, os demais herbicidas não foram prejudicados quando aplicados com vinhaça. O 2,4-D e a ametryne melhoraram a sua ação no controle de plantas daninhas e seu efeito residual aumentou, quando aplicados em mistura com vinhaça. O tebuthiuron e o oryzalin apresentaram comportamento semelhante no controle das plantas daninhas, nos dois sistemas de aplicação. O diuron aplicado em mistura com vinhaça apresentou resultados altamente negativos no controle das planta daninhas.

UNITERMOS: Herbicidas, vinhaça, cana-deaçúcar

\section{SUMMARY}

\section{VIABILITY OF APPLYING HERBICIDES IN "VINHAÇA> TO CONTROL WEEDS IN RATOON SUGARCANE}

In this study, herbicides were applied in "vi nhaça" (liquid residue of alcohol distillation) and at the usual way. Herbicides used were oryzalin, diuron, 2,4-D, ametryn and tebuthiuron. The application in "vinhaça> was done with a tank-car of 7,000 liters capacity. The tank was in connection with a spraying boom. Special design of the nozzles worked as jet pump, in order to have a good distribution of the solution on to the soil surface. A 36 HP pump controlled the amount of spray, which was of 25,000 liters per hectare. To spray as usual, a John Bean sprayer pump was used, having 16 nozzles teejet 110.04 , working at pressure of $1,4 \mathrm{~kg} / \mathrm{cm}^{2}$. To compare the treatments, a split plot design, with four replications was used.

All the herbicides, except diuron showed good performance in weed control, when applied in "vinhaca". Diuron behaviour in "vinhaca" was very poor. Ametryn and 2,4 - D showed better characteristics as weed killers when applied in "vinhaça". No differences in the performance of tebuthiuron and oryzalin, in weed control, were observed when applied with or without "vinha ça".

KEYWORD: Herbicides "vinhaça., sugarcane. 


\section{INTRODUÇÃO}

A vinhaça é um resíduo líquido resultante da produção de álcool ou de leveduras, através do sistema de fermentação biológica. O volume de vinhaça obtido, nas destilarias de álcool, é de aproximadamente 131 para cada litro de álcool produzido. Há muito tempo, a vinhaça vem se constituindo em problema social, face ao seu alto poder poluente. Apesar disto, seu aproveitamento só mereceu a devida atenção, a partir do momento em que se constatou que, quando restituido racionalmente à lavoura canavieira, constituia uma considerável economia ao seu usuário. Comprova-se, que a vinhaça pode ser aproveitada como fertilizante orgânico e mineral, pelo fato de possuir em sua composição a maioria dos nutrientes necessários às plantas.

Entre as maneiras preconizadas para a aplicação da vinhaça ao canavial, está o uso de caminhões-tanques, munidos de cano perfurado. Este sistema permite uma distribuição relativamente uniforme da vinhaça ao solo, principalmente se a vazão for controlada por moto-bomba e não simplesmen te por gravidade. Neste caso, haveria a possibilidade de se misturar o herbicida à vinhaça, distribuindo-os ao solo numa só operação.

Encontrou-se na lite ratura, ape nas um trabalho preliminar, realizado por Buss \& Silva (4) propondo a possibilidade de aplicar herbicidas em mistura com vinhaça. Os resultados obtidos sugerem que os herbicidas oryzalin (3,5-dinitro-N,N-dipropil sulfanilamida)

e tebuthiuron (N-(5-(1,1-dimetiletil)1,3,4 tiadiazol-2-il) - 1,3-N,N' - dimetil uréia) podem ser aplicados com a vinhaça. Aparentemente, o alto teor de matéria orgânica e a alta temperatura da vinhaça não interferiram na ação dos herbicidas no controle de plantas daninhas.

Os teores de matéria orgânica exercem influência marcante sobre o comportamento dos herbicidas. Segun- do Wolcott (20), fenômenos de adsorção, lixiviação, volatilidade e bioatividade dos defensivos, são normalmente melhor correlacionados com o teor de matéria orgânica do solo. Segundo Mata (14), as interações entre as moléculas dos herbicidas e as frações coloidais do solo são influenciadas consideravelmente pela umidade, temperatura, $\mathrm{pH}$, conteúdo de minerais e matéria orgânica do solo, bem como a capacidade de troca iônica do solo. Ainda segundo o autor, é dificil estabelecer a importância de cada uma das características físico-químicas do solo, em relação aos mecanismos de decomposição ou desaparecimento dos herbicidas no solo. Entretanto, o autor considera que é comum ocorrer menor persistência de herbicidas em solos tropicais, onde existem condições de umidade e de temperatura elevadas.

De acordo com Klingman et al. (12) e Mata (14), todas as substâncias químicas são voláteis em alguma intensidade, dependendo de sua pressão de vapor, estado físico em que se encontram e temperatura do ambiente. Em razão disso, os herbicidas volatilizam da superficie do solo, especialmente quando esta está úmida. A pressão de vapor de um determinado produto é responsável pela maior ou menor volatilização deste produto. De acordo com Klingman et al. (12) os gases resultantes da volatilização de um herbicida podem ser ou não tóxicos às plantas. Desse modo, é de se esperar que a ação de muitos herbicidas possa ser aumentada ou diminuida, quando aplicados em condições de altas temperaturas.

É prática usual, em certos casos, a mistura de herbicidas com outros defensivos e fertilizantes visando normalmente, o aspecto econômico das aplicações. As características físicas e químicas de cada um dos compostos que integram a mistura podem determinar sinergismo, antagonismo ou indiferença na ação do produto, quando comparado à sua aplicação isolada. Estudos condu zidos por Klosterboer \& Bardzley (13), 
com misturas de herbicidas em soluções nitrogenadas, mostram que quanto menor a percentagem do ingrediente ativo do herbicida e quanto mais eficiente o surfactante e outros componentes do produto formulado, ocorreu menor efeito adverso em dispersar a estabilidade da solução. Por outro lado, aumentando-se a molaridade da solução nitrogenada, diminuía sen sivelmente a estabilidade de dispersão dos herbicidas. Scott e Scott (16), estudando a viabilidade de se incorporar herbicidas em grânulos de fertilizantes, concluiram que em aplicação em área total era vantajosa esta prática, além de reduzir o custo do transporte e da aplicação.

O objetivo do presente trabalho é o de verificar a viabilidade técnica do uso de herbicidas em mistura com vinhaça, para o controle de plantas daninhas em soqueiras de cana-de-açúcar.

\section{MAT ERIAIS E MÉTODOS}

A pesquisa foi conduzida na Usina Açucareira de Cillos em Santa Bárbara d'Oeste, no Estado de São Paulo. O experimento foi instalado em solo de textura argilosa, caracterizado como Latossolo Vermelho Escuro. Os herbicidas foram aplicados nos dias 11 e 16 de novembro de 1976, sendo que no dia 11 foram aplicados os tratamentos em mistura com vinhaça, e no dia 16 , os tratamentos pelo sistema convencional de aplicação de herbicidas. O experimento foi instalado em cultura já estabelecida da cultivar CB 41-76, a qual representa $32,5 \%$ da área canavieira do Estado de São Paulo, segundo IAA-Planalsucar (11).

Os herbicidas utilizados foram oryzalin à $2,0 \mathrm{~kg} / \mathrm{ha}$, tebuthiuron à 1,2 $\mathrm{kg} / \mathrm{ha}$, diuron [3-(3,4-diclorofenil)-1,1, dimetil-uréia) à 2,4 kg/ha, 2,4-D (ácido 2,4diclorofenoxiacético) à $2,4 \mathrm{~kg} /$ ha e ametryne [2-(etilamino)-4-(is opropilamino) -6(metiltio)-S-triazinal â 2,4 $\mathrm{kg} / \mathrm{ha}$, todas estas doses expressas em ingrediente ativo.
Para a distribuição dos herbicidas em mistura com vinhaça, usou-se um caminhão provido com tanque de capacidade de 7.000 litros, conforme sistema descrito por Gurgel \& Guimarães (9). 0 caminhão movia-se a uma velocidade de $2,5 \mathrm{~km} / \mathrm{h}$, com uma vazão de $25.0001 /$ ha. A temperatura da vinhaça no momento da mistura com o herbicida era de $80^{\circ} \mathrm{C}$. A mistura do herbicida com a vinhaça foi realizada na boca de descarga de vinhaça da usina, obedecendo aos seguintes critérios:

a) mistura do herbicida com água num balde;

b) no tanque do caminhão era colocado $1 / 4$ do seu volume com vinhaça;

c) simultaneamente com a introdução da vinhaça, era derramado o herbicida diluído em água, até o tanque estar aproximadamente com metade do seu volume;

d) o volume do tanque era completado com vinhaça. A vinhaça, ao ser introduzida pela parte superior do tanque, proporcionava uma forte agitação hidráulica no seu interior.

A distribuição dos herbicidas com equipamento convencional foi feita com pulverizador "John Bean". A barra de aplicação estava provida com 16 bicos "Teeject" 110.04. Os bicos estavam distanciados a $45 \mathrm{~cm}$ um do outro, cobrindo uma faixa de $7 \mathrm{~m}$ de largura. A pressão de aplicação era de 1,4 $\mathrm{kg} / \mathrm{cm}^{2}$ e a vazão era de $4001 /$ ha. A velocidade do trator na aplicação era de $3,6 \mathrm{~km} / \mathrm{h}$.

Usou-se delineamento experimental de blocos casualizados com parcelas subdivididas, com quatro repetições. As parcelas eram constituídas por tratamentos com vinhaça e sem vinhaça. As subparcelas eram constituídas por diferentes herbicidas. Cada subparcela era formada por cinco linhas de cana-deaçúcar, distanciadas $1,40 \mathrm{~m}$ entre si, com $20 \mathrm{~m}$ de comprimento. A área útil era formada pelas três linhas centrais das subparcelas. Os tratamentos com herbicidas foram comparados com as testemunhas com e sem vinhaça, nas 
quais se realizou capina manual de acordo com as práticas adotadas na usina. Estas capinas foram realizadas aos $70 \mathrm{e}$ 110 dias após a instalação do experimento.

Para a instalação do experimento, inicialmente procedeu-se ao enleiramento e queima da palha resultante da safra anterior, operação esta que foi realizada em fins de outubro de 1976. Em seqüência, foi feito um cultivo nas entrelinhas da cultura de cana-de-açúcar já estabelecida. Este cultivo foi feito com grade de discos, trabalhando à uma profundidade aproximada de $20 \mathrm{~cm}$. Após este preparo do terreno, permaneceram no local alguns torrões com diâmetro de até $5 \mathrm{~cm}$, bem como pequenas quantidades de restos de cultura da safra anterior.

Contagem e classificação de plantas daninhas foram feitas aos 20, 70 e 120 dias após a instalação do experimento. A contagem das plantas daninhas foi feita em área de $5 \mathrm{~m}^{2}$ por subparcela, em sua área central, tendo sido analisa das separadamente as espécies monocotiledôneas e dicotiledôneas.

\section{RESULTADOS E DISCUSSÃO}

Aos 20 dias após a aplicação dos herbicidas (DAA), foi feita a primeira contagem das plantas daninhas, estando os resultados apresentados no Quadro 1. A população de monocotiledôneas nas testemunhas era maior do que a de dicotiledôneas, principalmente no tratamento com vinhaça. A elevada temperatura da vinhaça deve ter quebrado a dormência de muitas sementes de gramineas existentes no solo, promovendo a sua germinação. Diferenças significativas foram verificadas para herbicidas e para a interação de herbicidas e vinhaça, nas contagens de monocotiledôneas e do total de plantas daninhas. As diferenças, na população de dicotiledôneas, foram significativas apenas para os herbicidas.
Nos tratamentos com vinhaça, todos os herbicidas, com exceção de diuron, apresentaram comportamento semelhante no controle de monocotiledõneas, ao nivel de $95 \%$ de probabilidade. $\mathrm{O}$ diuron igualou-se à testemunha com vinhaça. Nos tratamentos sem vinhaça, o tebuthiuron apresentou o melhor resultado no controle de monocotiledôneas, mas esta superioridade foi significativa apenas em relação ao 2,4-D. No aspecto global, houve destaque para ametryne no controle de monocotile dôneas, que no entanto, não diferiu significativamente de tebuthiuron e de oryzalin.

No controle de dicotiledõneas, houve diferenças significativas para herbicidas, mas não nas aplicações com ou sem vinhaça. O 2,4-D apresentou o melhor controle, mas este não foi significativo em relação à oryzalin.

No controle total de plantas daninhas aos 20 DAA, a tendência foi de ser semelhante ao controle de monocotiledõneas, pelo fato de serem em maior número. Houve significância para diferenças entre herbicidas, tan to aplicados com, como sem vinhaça. Nos tratamentos com vinhaça, o diuron mostrou-se ineficaz no controle de plantas daninhas, o que poderia ter sido causado pela ação da matéria orgânica, da temperatura ou de outro fator inerente à vinhaça. Conforme Meggitt (15), Wolcott (20), Chang (5), Klingman et al. (12), Mata (14) e Forster (7), a matéria orgânica do solo tende a imobilizar grande parte de herbicida aplicado ao solo, de modo que o mesmo poderia ter ocorrido em relação ao diuron e à matéria orgânica existente na vinhaça. Por outro lado, devido ao aumento da pressão de vapor com a elevação da temperatura e considerando as condições de umidade do solo, parte apreciável do produto teria perdido sua ação. Horowitz e Herz-linger (10) constataram que o diuron perdeu sua ação, após duas semanas, quando pulverizado em superfícies úmidas, em clima quente e ensolarado. 
QUADRO 1 - Populaçáo de plantas daninhas, 20, 70 e 120 dias após a aplicaçáo dos herbicidas.

\begin{tabular}{|c|c|c|c|c|c|c|c|c|c|c|}
\hline \multirow{2}{*}{$\begin{array}{l}\text { PLANTAS } \\
\text { DANINHAS } \\
\end{array}$} & \multirow{2}{*}{ HERBICIDAS } & \multicolumn{3}{|c|}{ N.O MÉDIO DE PLANTAS POR $5 \mathrm{~m}^{2}-20$ DAA } & \multicolumn{3}{|c|}{ N.o MÉDIO DE PLANTAS POR $5 \mathrm{~m}^{2}-70$ DAA } & \multicolumn{3}{|c|}{ N.O MEDIO DE PLANTAS POR $5 \mathrm{~m}^{2}-120$ DAA* } \\
\hline & & C/VINHAÇA & S/VINHAÇA & MÉmiA & C/VINHAÇA & S/VINHAÇA & MÉDUA & C/VINHAÇA & S/VINHAÇA & MÉDIA \\
\hline \multirow[t]{2}{*}{$\begin{array}{l}\text { MONOCOTI } \\
\text { LEDONEAS }\end{array}$} & $\begin{array}{l}\text { Oryzalin } \\
\text { Diuron } \\
2.4-\mathrm{D} \\
\text { Ametryne } \\
\text { Tebuthiuron } \\
\text { Testemunha } \\
\end{array}$ & $\begin{array}{r}25.00 \mathrm{~b} \\
158.75 \mathrm{a} \\
41.75 \mathrm{~b} \\
9.50 \mathrm{~b} \\
23.25 \mathrm{~b} \\
142.75 \mathrm{a} \\
\end{array}$ & $\begin{array}{c}15.75 \mathrm{ab} \\
19,75 \mathrm{ab} \\
34.25 \mathrm{a} \\
8.25 \\
0.50 \mathrm{ab} \\
26,75 \mathrm{ab} \\
\end{array}$ & $\begin{array}{c}20,37 \mathrm{~cd} \\
89,25 \mathrm{a} \\
38,00 \mathrm{bc} \\
8.87 \mathrm{~d} \\
11,87 \mathrm{~d} \\
84,75 \mathrm{ab} \\
\end{array}$ & $\begin{array}{c}30,00 \mathrm{~cd} \\
72,25 \mathrm{ab} \\
49,75 \mathrm{bc} \\
14,25 \mathrm{~d} \\
22,50 \mathrm{~d} \\
102,75 \mathrm{a} \\
\end{array}$ & $\begin{array}{l}10.75 \mathrm{~b} \\
30.00 \mathrm{ab} \\
48.25 \mathrm{a} \\
26.75 \mathrm{ab} \\
10.00 \mathrm{~b} \\
47.75 \mathrm{a} \\
\end{array}$ & $\begin{array}{l}20.37 \mathrm{c} \\
51.12 \mathrm{~b} \\
49.00 \mathrm{~b} \\
30.50 \mathrm{c} \\
16,25 \mathrm{c} \\
75.25 \mathrm{a} \\
\end{array}$ & $\begin{array}{r}17.50 \\
31.50 \\
21,75 \\
10.75 \\
8.50 \\
0.00 \\
\end{array}$ & $\begin{array}{r}7.75 \\
15.50 \\
13,25 \\
8,50 \\
5.50 \\
0.00 \\
\end{array}$ & $\begin{array}{c}12.62 \mathrm{~b} \\
23.50 \mathrm{a} \\
17.50 \mathrm{ab} \\
9.62 \mathrm{c} \\
7.00 \mathrm{c} \\
0.00 \mathrm{c} \\
\end{array}$ \\
\hline & MÉDIA & $66.83 \mathrm{~A}$ & $17,54 \mathrm{~A}$ & 42,19 & $48,48 \mathrm{~A}$ & $28,92 \mathrm{~B}$ & 38,75 & $15.00 \mathrm{~A}$ & $8.42 \mathrm{~A}$ & 11,71 \\
\hline \multirow[t]{2}{*}{$\begin{array}{l}\text { DICOTI } \\
\text { LEDONEAS }\end{array}$} & $\begin{array}{l}\text { Oryzalin } \\
\text { Divron } \\
2.4 . \mathrm{D} \\
\text { Ametryne } \\
\text { Tebuthiuron } \\
\text { Testemunha } \\
\end{array}$ & $\begin{array}{r}4.00 \\
18.50 \\
2.50 \\
6.50 \\
14.50 \\
38,00 \\
\end{array}$ & $\begin{array}{r}7.25 \\
15.00 \\
8,00 \\
12,75 \\
30.25 \\
25.50 \\
\end{array}$ & $\begin{array}{c}5,62 \mathrm{bc} \\
16,75 \mathrm{ab} \\
5,25 \\
9,62 \mathrm{~b} \\
17,37 \mathrm{ab} \\
31,75 \mathrm{ab} \\
\end{array}$ & $\begin{array}{l}37.75 \\
31,00 \\
42.75 \\
11,25 \\
15,25 \\
67,00 \\
\end{array}$ & $\begin{array}{l}24.25 \\
24.75 \\
23.25 \\
28.25 \\
22.00 \\
47.25 \\
\end{array}$ & $\begin{array}{l}31.00 \mathrm{~b} \\
27.87 \mathrm{~b} \\
33.00 \mathrm{~b} \\
19.75 \mathrm{~b} \\
18.62 \mathrm{~b} \\
57.12 \mathrm{a} \\
\end{array}$ & $\begin{array}{l}6.25 \\
4.25 \\
4.00 \\
2.00 \\
1.75 \\
0.00 \\
\end{array}$ & $\begin{array}{l}2.75 \\
2.50 \\
1.75 \\
3.25 \\
5.75 \\
0.00 \\
\end{array}$ & $\begin{array}{l}4.50 \mathrm{a} \\
3,75 \mathrm{a} \\
2.87 \mathrm{a} \\
2.62 \mathrm{a} \\
3.75 \mathrm{a} \\
0.00 \mathrm{~b} \\
\end{array}$ \\
\hline & MEEDIA & $14,00 \mathrm{~A}$ & $14,79 \mathrm{~A}$ & 14,39 & $34,17 \mathrm{~A}$ & $28,29 \mathrm{~A}$ & 31.23 & $304 \mathrm{~A}$ & $2.67 \mathrm{~A}$ & 2.85 \\
\hline \multirow[t]{2}{*}{ TOTAL } & $\begin{array}{l}\text { Oryzalin } \\
\text { Diuron } \\
2,4 . \mathrm{D} \\
\text { Ametryne } \\
\text { Tebuthiuron } \\
\text { Testemunha } \\
\end{array}$ & $\begin{array}{r}29.00 \mathrm{~b} \\
177.25 \mathrm{a} \\
44.25 \mathrm{~b} \\
16.00 \mathrm{~b} \\
37.75 \mathrm{~b} \\
180.75 \mathrm{a} \\
\end{array}$ & $\begin{array}{l}23.00 \mathrm{a} \\
34.75 \mathrm{a} \\
42.25 \mathrm{a} \\
21.00 \mathrm{a} \\
20.75 \mathrm{a} \\
52,25 \mathrm{a} \\
\end{array}$ & $\begin{array}{r}26,00 \mathrm{~b} \\
106,00 \mathrm{a} \\
43,25 \mathrm{~b} \\
18,50 \mathrm{~b} \\
29,25 \mathrm{~b} \\
116,50 \mathrm{a}\end{array}$ & $\begin{array}{c}67,75 \mathrm{bc} \\
103,25 \mathrm{ab} \\
92,50 \mathrm{~b} \\
25,50 \mathrm{~d} \\
37,75 \mathrm{~cd} \\
169,75 \mathrm{a} \\
\end{array}$ & $\begin{array}{l}39.50 \mathrm{bc} \\
54.75 \mathrm{ab} \\
71.50 \mathrm{bc} \\
55.00 \mathrm{abc} \\
32.00 \mathrm{c} \\
95.00 \mathrm{a}\end{array}$ & $\begin{array}{c}53,62 \mathrm{bc} \\
79,00 \mathrm{~b} \\
82,00 \mathrm{~b} \\
40,25 \mathrm{c} \\
34,87 \mathrm{c} \\
132,37 \mathrm{a} \\
\end{array}$ & $\begin{array}{c}23.75 \mathrm{~b} \\
35.75 \mathrm{a} \\
25.75 \mathrm{ab} \\
12.75 \mathrm{c} \\
10.25 \mathrm{c} \\
0.00 \mathrm{~d}\end{array}$ & $\begin{array}{r}10.50 \mathrm{a} \\
18.00 \mathrm{a} \\
15.00 \mathrm{a} \\
11.75 \mathrm{a} \\
11.25 \mathrm{a} \\
0.00 \mathrm{~b} \\
\end{array}$ & $\begin{array}{l}17.12 \mathrm{bc} \\
26.87 \mathrm{a} \\
20.37 \mathrm{~b} \\
12.25 \mathrm{~cd} \\
10.75 \mathrm{~d} \\
0.00 \mathrm{e}\end{array}$ \\
\hline & MÉDIA & $80,83 \mathrm{~A}$ & $32,33 \mathrm{~A}$ & 56.58 & $82,75 \mathrm{~A}$ & $57,96 \mathrm{~A}$ & 70.35 & $18.04 \mathrm{~A}$ & $11.08 \mathrm{~A}$ & 14,56 \\
\hline
\end{tabular}

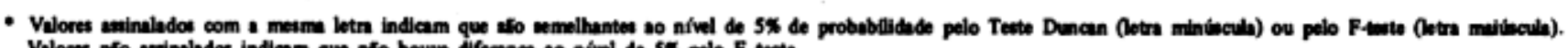

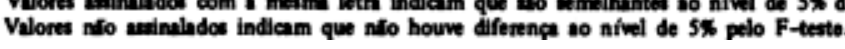


Os valores das contagens de plantas daninhas realizados aos 70 DAA, são mostrados no Quadro 1. A população de monocotiledôneas da testemunha com vinhaça diminui em relação à contagem realizada aos 20 DAA, provavelmente devido à competição interespecifica.

As diferenças no número de gramineas foram significativas para a vinhaça, para os herbicidas e para a interação de herbicidas e vinhaça. O número de monocotiledôneas foi significativamente superior em parcelas tratadas com vinhaça, àquelas sem vinhaça. Dos herbicidas que foram aplicados em mistura com vinhaça, os que tiveram melhor desempenho foram ametryne, tebuthiu ron e oryzalin. O diuron não foi melhor do que a testemunha, em aplicações com vinhaça, confirmando as observações realizadas aos 20 DAA. O 2,4-D, por sua vez, em aplicações com vinhaça, manteve bom controle de monocotiledõneas, embora nas aplicações pelo sistema convencional e de acordo com Beale (3), Alves (1), Klingman et al. (12) e Victória Filho (19), o seu período de ação não vá além de 60 dias. Neste caso, é provável que os colóides orgânicos da vinhaça tenham retido o produto, com liberação gradual, prolongando o seu efeito residual. Este aspecto é de grande importância prática, pois que uma das restrições do produto é exatamente o seu período residual curto.

Quanto às dicotiledôneas, houve apenas significância para herbicidas, que não diferiram entre si, mas foram superiores à testemunha. A grande diversidade de espécies dicotiledôneas foi marcante, o que parece ter influído na menor resposta destas espécies aos diversos tratamentos.

O comportamento do total de plantas daninhas foi significativamente influenciado pela ação de diferentes herbicidas, havendo, também diferenças significativas para interação de herbicidas e vinhaça. A ametryne e o tebuthiuron determinaram menor popula- cão de plantas daninhas, quer em aplicações com vinhaça, quer em aplicações sem vinhaça. Neste último caso, também oryzalin e 2,4-D foram incluidos no primeiro grupo. Observa-se que os tratamentos com vinhaça foram mais seletivos para os herbicidas, o que pode ser devido, em parte, à maior população de plantas daninhas que ocorreram nestas condições.

Os valores das contagens feitos aos 120 DAA são mostrados no Quadro 1. Nesta ocasião, grande número de espécies botânicas já haviam chegado ao fim do ciclo e se notava um predomínio total de marmelada (Brachiaria plantaginea (Link) Hitch). Para o controle desta espécie, o tebuthiuron e a ametryne mostraram-se significativamente superiores aos demais herbicidas. A área testemunha havia sido capinada, de modo que estava livre de concorrência de plantas daninhas. No controle de dicotiledôneas, presentes em pequeno número, a testemunha capinada fo $i$ significativamente superior do que o controle obtido em parcelas tratadas com herbicidas. A ação residual da ametryne e do tebuthiuron, aplicados em vinhaça, foi a que mais se prolongou neste período de 120 dias. O tebuthiuron, segundo Elanco (6) tem realmente uma ação muito prolongada no solo, de modo que os resultados obtidos coincidem com as características do produto. O ametryne, no entanto, como regra geral, não apresenta efeito tão prolongado, de acordo com dados obtidos por Azzi \& Fernandes (2), Garcia (8) e Victória Filho (19). Este fato sugere que o produto tenha sido adsorvido pelos colóides orgânicos da vinhaça, para ser liberado, paulatinamente, para o controle das plantas daninhas. Segundo Klingman et al. (12), o ametryne é adsorvido reversivelmente pelos colóides orgânicos do solo, o que pode justificar o seu comportamento em mistura com vinhaça.

A Figura 1 mostra a eficiência dos herbicidas no controle das plantas daninhas, em relação às respectivas teste- 

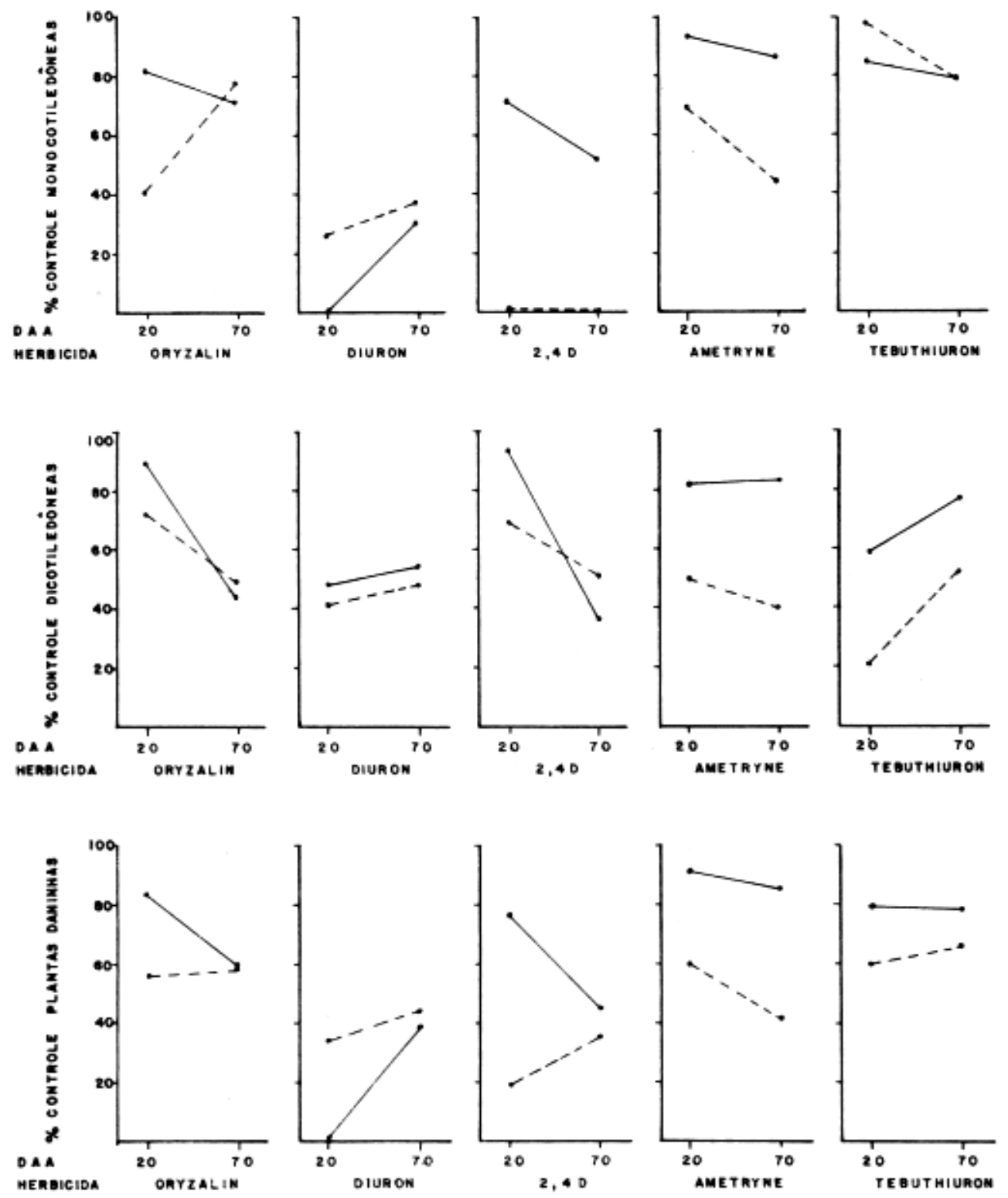

FIGURA I - Eficiência dos herbicidas no controle de plantas daninhas, em relação às testemun has com e sem vinhaça.

munhas com e sem vinhaça. Pelas análises até aqui realizadas, constatou-se que a população das plantas daninhas, principalmente de monocotiledôneas, 
aumentou na parcela testemunha, pela adição da vinhaça. Isso mostra que a população de plantas daninhas a ser controlada nas áreas com vinhaça, era consideravelmente superior às área sem vinhaça. Visto sob este aspecto, nota-se que, de modo geral, a percentagem de controle, em aplicações com vinhaça, foi superior às aplicações sem vinhaça. Neste sentido, existem casos bem típicos, mesmo com 2,4-D, em que ocorreu um desnivel realmente acentuado, no controle de gramíneas. O 2,4D, conforme Suáres \& Sánches (18), Souza (17) e Alves (1) não oferece controle à planta daninha gramínea, o que ocorreu no presente trabalho. No entanto, em vinhaça, teve um comportamento bem diferente, com controle de $70 \%$ aos 20 DAA e de $52 \%$ aos 70 DAA. O ametryne teve também melhor comportamento quando aplicado com vinhaça, mantendo, por outro lado, maior efeito residual, nestas condições de aplicação. A ação do tebuthiuron foi semelhante, nos dois modos de aplicação, no controle de monocotiledôneas, mas foi melhor no controle de dicotiledôneas, quando aplicado com vinhaça. Oryzalin mostrou melhor eficiência quando aplicado em vinhaça aos 20 DAA, mas esta diferença desapareceu nas contagens feitas aos 70 DAA. O diuron, conforme já amplamente analisado, foi ineficaz, no controle de monocotiledõneas, quando aplicado em vinhaça.

\section{LIT ERATURA CITA DA}

1- Alves, A. Cultura da cana - uso de herbicidas. Campinas, CATI, 1975. 20p. (Boletim Técni$\mathrm{co}, 83)$.

2 - Azzi, G.M. \& Fernandes, J. Controle pré-emergente de ervas daninhas em canaviais tratados com ametrin, simazin e 2,4-D. Brasil açucareiro, Rio de Janeiro, 72(5):22-27, 1968.

3 - Beale, F.A. O Controle químico da erva daninha nos canaviais. A Fazenda, Porto Rico, 45(9):42-43, 1950.

4 - Buss, A. \& Silva, S.A. Aplicaçáo dos herbicidas oryzalin e tebuthiuron em mistura com vi- nhaça em cana soca. In: Seminário Brasileiro de Herbicidas e Ervas Daninhas, 11.', Londrina, 1976. Resumos, p.65-66.

5 - Chang, S.S. Adsorption, desorption, movement, and dissipation of tebuthiuron in soll. Oklahoma, Oklahoma State University. (Dissert.). Oklahoma State University, Oklahoma, 1975. 41p.

6 - Elanco Produtos Agropecuários e Industriais. Perflan 80, herbicida de pré-emergència, seletivo, para a cultura de cana-de-açúcar. Sảo Paulo, Elanco, 1975. 4p.

7 - Forster, $R$. Uso seguro de herbicidas na agricultura. Curitiba, 1976. (mimeografado).

8 - Garcia, R.C. Herbicidas em caña de axúcar. Las Villas (Cuba). Facultad de Ciencias Agropecuárias, 1972. 28p. (Boletim, 5).

9 - Gurgel, M.N. do A. \& Guimaráes, E. Um sistema de aplicaçáo de vinhaça. Boletim téenico Copersucar, Sáo Paulo, (3):3, 1976.

10 - Horowitz, M. \& Herzlinger, G. Soil conditions affecting the dissipation of diuron, fluometuron and propham from the soil surface. Weed Research, Oxford 14(4):257-259, 1973.

11 - IAA - PLANALSUCAR. Relatório Anual. Piracicaba, Planalsucar, $1976.88 \mathrm{p}$.

12 - Klingman, G.C.; Ashton, F.M. ; Noordhoff, L.J. Weed Science: principles and practices. New York, John Wiley, 1975. 431p.

13 - Klosterboer, A.D. \& Bardsley, C.E. Assessing compatibility of herbicides and nitrogen solutions. Weed Science, Urbana, 16(4):468470, 1968.

14 - Mata, O.A. Que sucede con los herbicidas en el suelo? Agricultura Técnica en México, México (11): 407-413, 1975.

15 - Meggitt, W.F. Herbicide activity in relation to soil type. In: International Symposium on Pesticides in the Soil. Michigan, State University, 1970. p. 139-141.

16 - Scott, M.R. \& Scott, E.M. Herbicides as fertilizer additives. Weed Research, Oxford, 2(4): 247-263, 1962.

17 - Souza, H.D. de. Experimento com herbicidas. Brasil Açucareiro, Rio de Janeiro, 66(2): 23-25, 1965.

18 - Suáres, P. \& Sánchez, L.C. Estudio comparativo sobre la efectividad de varios herbicidas em cana de azúcar. Acta Agron., Colombia, 6(3): 149-158, 1956.

19 - Victória Filho, R. Controle e fitotoxidade de herbicidas pré-emergentes na cultura de cana-de-açúcar (Saccharum afficinarum L.). In: Seminário Brasileiro de Herbicidas e Ervas Daninhas, 11. ${ }^{\circ}$ Londrina, 1976. Resumos, p.64.

20 - Wolcott, A.R. Retention of pesticides by organic materials in soils. In: International Symposium on Pesticides in the Soil. Michigan, Michigan St. Univ., 1970. p. 128-138. 